centre of the first UK marine park, home to seals and puffins.

Last week, the UK government ended a public consultation on the latest round of its attempts to manage conflicts between conservation and other maritime interests. Officials plan to create dozens of marine conservation zones (MCZs) around the UK coast, to introduce an extra level of protection for worthy sites. The move is part of a global effort to extend conservation measures on land to the coast and open seas.

But, as on land, conservation of marine areas is not popular with everyone, and the ambitious UK plans are in danger of running aground. Already, proposals for the Studland MCZ have been dropped for now, and plans for others are in danger. In fact, marine experts who originally identified 127 sites for MCZs around the British coastline now fear that, in the worst case, barely more than half will be realized.

The UK process sets up these zones in three waves. The first saw 31 proposed MCZs reduced to 27, which were designated in November 2013. A second tranche of designations initially featured 37 sites, but was whittled down to 23 even before the public consultation closed last week. (Studland Bay MCZ was one of the 14 that were chopped.) The third wave is meant to be set up before 2016 .

The United Kingdom is squaring up for a general election on 7 May, and even long-serving politicians are nervous about keeping their seats. Marine conservation is low on the agenda - especially the sort that annoys boat-owning voters. But the next government will have to take some tough decisions on marine protection. Because of the way the first two tranches of MCZ designation have progressed, the third will be left with difficult decisions on controversial sites that have been kicked into the long (sea)grass by the earlier rounds. These include not only Studland but also the important deep-water mud habitats of the Celtic Deep, and another sea-horse habitat off the Isle of Wight.

Crucially for the United Kingdom, failures at home are undermining its potential to show global leadership on marine conservation. Huge marine parks have been designated around UK territories such as the Chagos Islands in the Indian Ocean, and another was announced on 18 March for the Pitcairn Islands in the south Pacific. Significant ques-
"The UK government deserves credit for establishing the parks at all." tions remain over enforcement and monitoring of these overseas reserves, and must be solved if they are not to become what scientists call 'paper parks' - just a line on a map rather than something that does any good.

But the UK government deserves credit for establishing these parks at all. This is despite a recent setback for the Chagos reserve - a judge ruled last month that the park had been improperly declared by Britain because Mauritius, which has fishing rights in the archipelago, had not been fully consulted.

Later this year, the finalized United Nations Sustainable Development Goals are likely to include a commitment to protecting the oceans. Making good on this and on existing promises will require governments to disappoint some powerful vested interests that would prefer to keep access to marine areas unrestricted. And if rich nations wish to push the rest of the world to protect its marine wonders, they must first get their own houses in order. Scientists can help by promoting the value of places that lack the brand recognition of the Great Barrier Reef. If the world's seas are really going to be protected, mud and seagrass will have to be considered alongside tropical reefs.

\section{More on unicorns}

\section{A newly discovered tiny dinosaur sported an intriguing structural accessory.}

$\mathrm{H}$ ow do you go about hunting for unicorns? More specifically, let's say that you have found your unicorn, but then what? How would you know that it was a unicorn, rather than something else? How diagnostic, say, is that horn? Might there not be other creatures, as yet unimagined, that have unicorn-like horns but differ from unicorns (and everything else) in all kinds of unusual ways? Narwhals, for example, exist - and their unicorn-like horn is the only feature they have in common with unicorns. So what else might lurk out there in the great unknown? You know that unicorns don't number among the domestic beasts, says Jorge Luis Borges in his essay 'Kafka and his precursors', but, without seeing one, how do you know what a unicorn is "like"?

Palaeontology is always about hunting for unicorns. Because fossils sample diversity from the past that might not exist today, there is always a chance that one will dig up something that defies categorization. Such is the case for the tiny dinosaur described online in Nature by Xing Xu and colleagues (see go.nature.com/jsxjxv), and discussed further by Kevin Padian (go.nature.com/s6g2aw).

The dinosaur is about as far from Brontosaurus and other behemoths familiar to the museum visitor as might be imagined. It belongs to a little-known group of creatures whose body size has hitherto scaled inversely with the length of their names. It is only the third known example of a (deep breath) scansoriopterygid, the other two bearing the unwieldy handles Epidendrosaurus and Epidexipteryx. $\mathrm{Xu}$ and colleagues buck the trend by calling their creature Yi. Or, in full, Yi qi. This must be the shortest dinosaur name ever, and it is commensurate with the tiny size of scansoriopterygids, which could have looked thrushes or starlings in the eye. Although scansoriopterygids had feathers and cluster phylogenetically round the ancestry of birds and other feathered dinosaurs, they do not seem to have had flight feathers on their disproportionately long forelimbs. Reconstructions make them out to be rather like feathered lemurs, scampering along branches, perhaps wheedling insects out of crevices with their long, clawed fingers.

Except that Yi qi is different. Attached to each wrist is a strut, made of bone or calcified cartilage, which cannot simply be homologized with regular wrist or hand bones. The strut seems to be a new structure made from an accessory wrist bone, possibly a sesamoid — the kind of bone usually embedded in a tendon or muscle. The 'thumb' of the giant panda is made of just such a bone. The sesamoid of Yi qi (if that's what it is) is much larger, however, in relation to the animal as a whole - equal in length to the bones of the forearm. It had to be there for a reason, but what was it?

It is here that we enter unicorn territory - for no dinosaur, however unusual, has been found with anything like this feature. The authors are appropriately cautious, therefore, in their interpretation. They point to the hint of a suggestion that some soft tissue, preserved alongside these curious elements, represents what might have been a membrane that the sesamoid bone supported. From that, they suggest that Yi qi had membranous wings and might have glided from branch to branch, in much the same way as various tree-living mammals and reptiles do today. But it was probably not capable of powered flight as birds and bats are - and as were, presumably, the extinct pterosaurs, which were (one must stress) only distant relatives of dinosaurs and birds.

When, in the mid-1990s, the first dinosaurs with preserved feathers came to light, there was a great deal of celebration. However, evidence for the bird-like nature of dinosaurs had been accumulating for a while, so for many (though not all) people, feathered dinosaurs were a vindication rather than a challenge. Yi qi, by contrast, is something else. Here we have a feathered dinosaur and a close relative of birds that seems to have essayed an entirely different experiment $\rightarrow$ NATURE.COM To comment online, click on Editorials at: go.nature.com/xhunqv in aerial locomotion. For a feathered dinosaur to have traded feathers for a membrane in an aerofoil is something nobody could have predicted. Whether or not it is a unicorn has yet to be determined. 